\title{
Caffeic acid phenethyl ester triggers apoptosis through induction of loss of mitochondrial membrane potential in CCRF-CEM cells
}

\author{
Çı̆̆ır Biray Avcı • Cumhur Gündüz • Yusuf Baran • Fahri Şahin • \\ Sunde Yılmaz • Zeynep Ozlem Dogan · Güray Saydam
}

Received: 27 January 2010/ Accepted: 19 February 2010/Published online: 10 March 2010

(C) Springer-Verlag 2010

\begin{abstract}
Purpose CAPE (caffeic acid phenethyl ester) is one of the most valuable and investigated component of propolis which is composed by honeybees. In the current study, we aimed at examining apoptotic effects of CAPE on CCRFCEM leukemic cells and at determining the roles of mitochondrial membrane potential (MMP) in cell death.

Methods Trypan blue and XTT methods were used to evaluate the cytotoxicity. Apoptosis was examined by ELISA-based oligonucleotide and acridine orange/ethidium bromide dye techniques. Loss of mitochondrial membrane potential was evaluated using JC-1 dye by flow cytometric analysis and under fluorescent microscope.

Results We detected the time- and dose-dependent increases in cytotoxic effect of CAPE on CCRF-CEM cells. ELISA and acridine orange/ethidium bromide results showed that apoptotic cell population increased significantly in CCRF-CEM cells exposed to increasing concentrations of CAPE. On the other hand, there was significant loss of MMP determined in response to CAPE in CCRFCEM cells.
\end{abstract}

Ç. B. Avcı · C. Gündüz · S. Yılmaz · Z. O. Dogan

Department of Medical Biology, School of Medicine,

Ege University, Bornova, Izmir 35100, Turkey

Y. Baran

Department of Molecular Biology and Genetics,

Izmir Institute of Technology, Urla 35430, Turkey

F. Şahin · G. Saydam ( $₫)$

Department of Hematology, School of Medicine,

Ege University, Bornova, Izmir 35100, Turkey

e-mail: guray.saydam@ege.edu.tr
Conclusion This in vitro data by being supported with clinical data may open the way of the potential use of CAPE for the treatment of leukemia.

Keywords CAPE - ALL - Apoptosis .

Mitochondrial membrane potential · Cytotoxicity

\section{Introduction}

Acute lymphoblastic leukemia (ALL) is a hematological malignancy resulting from clonal proliferation of early B- and T-lymphocyte progenitors. It is characterized by increased accumulation of leukemic blast cells in bone marrow and extramedullary sites. Although high rates of hematological responses obtained from the current treatment protocols in the vast majority of patients, the emergence of resistance to applied anticancer agents decreases the efficiency of treatment (Crazzolara and Bendall 1999). Having poor outcomes, short-term survival rates, and serious side effects in response to chemotherapeutic agents in patients with ALL imposed basic science researchers and clinicians to investigate novel anticancer agents derived from the natural sources, such as plants, animals, and sea products. Likewise, the numbers of studies investigating the anticancer potential of natural products have been increasing significantly.

CAPE is a chemical and structural relative of flavanoids and an active component of propolis. It has antiviral, antiinflammatory, immunomodulatory, and antiproliferative effects in different conditions. Antiproliferative ability of CAPE has been considered as a new anticancer treatment modality and has been studied in many cancers and cell lines both in vivo and in vitro (Crazzolara and Bendall 1999; Borrelli et al. 2002; Son and Lewis 2002; Lee et al. 
2000; Demestre et al. 2009). Several studies reported that the antitumoral effect of CAPE was possibly related to the alteration of redox potentials resulting in apoptosis, suppression of lipid peroxidation, inhibition of ornithine decarboxylase, and protein synthesis, and inhibition of activation of nuclear factor kappa B (NF- $\kappa \mathrm{B}$; Li et al. 2000; Berger et al. 1992; Rao et al. 1992; Michaluart et al. 1999; Sud'ina et al. 1993; Fesen et al. 1994). Interestingly, it was also shown that CAPE exerts apoptotic effect and suppresses the growth of transformed cells in a specific manner (Chiao et al. 1995). However, the apoptotic effects of CAPE on CCRF-CEM acute lymphoblastic leukemia cells and, if so, the roles of mitochondrial membrane potential in programmed cell death are not investigated previously.

Mitochondria have a central role in cellular functions in both normal and cancerous cells. The impact of mitochondrial activities on cellular physiology is not only restricted to ATP supply, but also to generate reactive oxygen species (ROS), to regulate intracellular $\mathrm{Ca}^{2+}$ homeostasis, and more importantly to regulate apoptosis through cytochrome $c$ release (Gogvadze et al. 2008). Once the cytosolic effectors of apoptosis are activated, loss of mitochondrial membrane potential takes place, and cytochrome $c$ and some other proteins are released from the intermembrane space of mitochondria to cytoplasm. This process activates caspases and downstream targets resulting in apoptosis (Gogvadze et al. 2006). Since the statues of mitochondria during the glycolytic pathways are essential for the survival of cancer cells, strategies targeting the mitochondria may provide an important avenue for the treatment of various types of cancers. In fact, there are different chemotherapeutic agents that can specifically alter the mitochondrial membrane potential (Gogvadze et al. 2008; Wolvetang et al. 1994; Asoh et al. 1996; Schmidt-Mende et al. 2006; Neuzil et al. 2001, 2006, 2007; Yu et al. 2003).

In the present study, we aimed at investigating the possible cytotoxic and apoptotic effects of CAPE on CCRF-CEM leukemic cells and at clarifying the involvement of the changes in mitochondrial membrane potential in this apoptotic process.

\section{Materials and methods}

\section{Cell line and chemicals}

Human T-cell acute lymphoblastic leukemia cells (CCRFCEM) were obtained from ECACC (UK, No: 85112105). CAPE was obtained from Sigma Chemical (LM, USA). $200 \mu \mathrm{M}$ stock solution of CAPE was prepared and dissolved in dimethylsulfoxide (DMSO), and the final concentration of DMSO has never been more than $0.1 \%$ in the experiments. Trypan blue dye was obtained from
Biological Industries (Israel). MitoProbe JC-1 Assay Kit was obtained from Invitrogen (CA, USA). XTT Cell Proliferation Assay was obtained from Roche Diagnostics (Munchen, Germany). All the other chemicals and tissue culture supplies were obtained from Sigma (Deisenhofen, Germany) unless otherwise specified.

\section{Evaluation of cytotoxicity}

CCRF-CEM cell line grown in RPMI-1640 medium containing $2 \mathrm{mM}$ L-glutamine supplemented with $10 \%$ fetal bovine serum (FBS) and $1 \%$ penicillin/streptomycin was maintained at a density of $5 \times 10^{5}$ cells $/ \mathrm{ml}$ in a standard cell culture incubator at $37^{\circ} \mathrm{C}, 100 \%$ relative humidity, and $5 \% \mathrm{CO}_{2}$ atmosphere (Sahin et al. 2007). Prior to any experiment, cells were split at $5 \times 10^{5}$ cells $/ \mathrm{ml}$ in the RPMI 1640 medium, and cell suspensions were aliquoted into flasks for subsequent treatments. CAPE diluted in RPMI 1640 was used in treatments of $1 \mathrm{nM}, 10 \mathrm{nM}$, $100 \mathrm{nM}, 1 \mu \mathrm{M}, 10 \mu \mathrm{M}$, and $100 \mu \mathrm{M}$.

Cytotoxic assays and determination of $\mathrm{IC}_{50}$ (drug concentration that inhibits cell proliferation 50\% when compared to untreated controls) dose of CAPE in CCRF-CEM cells were performed by using Trypan blue dye exclusion and XTT assay as indicated in manufacturer's instruction.

Cytotoxicity of CAPE by XTT-based cytotoxicity assay was determined as follows:

Cells were seeded in 96-well tissue culture plates and incubated for $24 \mathrm{~h}$ without drug. After addition of drug, cells were incubated for $96 \mathrm{~h}$, and cell viability was assessed by using XTT-PMS mixture (XTT sodium salt; [2,3-bis (2-methoxy-4-nitro-5-sulfophenyl)-2H-tetrazolium-5-carboxanilide inner salt], phenazine methosulfate (N-methylphenazonium methyl sulfate salt)], as recommended by supplier. Formazan formation was quantified spectrophotometrically at $490 \mathrm{nM}$ using a microplate reader (Bio-Rad, Coda, Richmond, CA).

Evaluation of apoptosis

Apoptosis was evaluated using Cell Death Detection ELISA assay (Roche Diagnostics, USA), and acridine orange/ethidium bromide method under fluorescence microscope. CAPE-induced apoptosis of CCRF-CEM cells was evaluated by using Cell Death Detection ELISA ${ }^{\text {PLUS }}$ assay according to manufacturer's instructions. Briefly, untreated control and CAPE-treated cells were processed and analyzed for cytotoxic histone-bound DNA fragments. CCRF-CEM cells were exposed to $10 \mu \mathrm{M}$ CAPE for $24,48,72$, and $96 \mathrm{~h}$. Changes in apoptosis rate were illustrated as the apoptotic index increased over the untreated control group. The absorbance, proportional to the degree of cell viability, was determined after addition of $2,2^{\prime}$-azino-di 
[3-ethylbenzthiozolin-sulfonate], as substrate at $15 \mathrm{~min}$ by ELISA reader (Bio-Rad-Coda, Hercules, CA, USA) at $595 \mathrm{~nm}$. The apoptosis level was calculated by the formula $A_{\mathrm{s}} / A_{\mathrm{o}}$, where $A_{\mathrm{s}}$ represents the experimental sample absorbance, and $A_{\mathrm{o}}$ represents the average absorbance produced in the assay using lysate from untreated cells. Apoptotic levels of control cells at each time point were defined as 1.0.

In addition, apoptosis was also determined morphologically after staining with acridine orange/ethidium bromide by fluorescence microscopy. Briefly, the cells were washed with cold $1 \times$ PBS and adjusted to the cell density of $1 \times 10^{6}$ cells $/ \mathrm{ml}$ in $1 \times$ PBS. Acridine orange and ethidium bromide $(1: 1, \mathrm{v} / \mathrm{v})$ were added to the cell suspension in final concentrations of $100 \mu \mathrm{g} / \mathrm{ml}$. After 30-min incubation of the cells, the cellular morphology was evaluated by fluorescence microscopy (Olympus, Japan). Apoptotic cells were essentially characterized by nuclear condensation of chromatin and/or nuclear fragmentation. Three hundred cells were evaluated for apoptosis and/or necrosis for each sample. When more than $50 \%$ of the pre-apoptotic plus apoptotic to total cell ratio was positive, the result was accepted positive for apoptosis.

Evaluation of mitochondrial membrane potential using JC-1 by flow cytometry and florescence microscope

Loss of the mitochondrial membrane potential was detected by using MitoProbe ${ }^{\mathrm{TM}}$ JC-1 Assay Kit by flow cytometry (Invitrogen, OG, USA). JC-1 (5,5',6,6'-tetrachloro$1,1^{\prime}, 3,3^{\prime}$,tetraethylbenzimidazolocarbocyanine iodide) has been widely used as a probe for cytofluorimetric analysis of the mitochondrial membrane potential. In apoptotic cells, JC-1 enters the cytoplasm as a monomer, emitting $527 \mathrm{~nm}$ (green fluorescence) after excitation at $490 \mathrm{~nm}$, but in healthy cells it is taken up by the mitochondria, the lipophilic cationic dye accumulates within the negatively charged, hyperpolarized mitochondrial matrix, and forms JC-1 aggregates that emit at $590 \mathrm{~nm}$ (red fluorescence; Cossarizza et al. 1993). Apoptotic cells were illustrated by the increase in green/red ratio evaluated by either fluorescence microscope or flow cytometry (Salvioli et al. 1997; Baran et al. 2007a; Swerts et al. 2004).

In order to assess the integrity of the mitochondrial membrane, $1 \times 10^{6} \mathrm{CCRF}-\mathrm{CEM}$ cells treated with CAPE were suspended in $1 \mathrm{ml}$ of warm media. The cells were labeled with $10 \mu \mathrm{l}$ of JC-1 $(200 \mu \mathrm{M})$ and incubated at $37^{\circ} \mathrm{C}$, $5 \% \mathrm{CO}_{2}$ for $30 \mathrm{~min}$. Excess amount of dye was removed by washing with $1 \times$ PBS. Pelleted cells were resuspended in $1 \times$ PBS and analyzed via flow cytometer with excitation wavelength of $480 \mathrm{~nm}$, using appropriate emission filters for Alexa Fluor 488 dye and R-phytoerythrin. The changes in mitochondrial membrane potential in these cells were also analyzed under fluorescence microscope.
Statistical analysis

Statistical analyses were conducted using SPSS statistical package program. Non-linear regression analyses were used for the relationships between different variables. Student's $t$ test was used to compare the means. $P$ values $<0.05$ were considered statistically significant.

\section{Results}

Effects of CAPE on proliferation and viability of human CCRF-CEM cells

We have shown antiproliferative effects of CAPE on CCRF-CEM cells by both XTT cell proliferation and trypan blue dye exclusion assays. The results showed that there were dose- and time-dependent decreases in cell proliferation and viability when compared to untreated controls.

There were $43,49,56$, and $60 \%$ decreases in cell proliferation in CCRF-CEM cells exposed to $10 \mu \mathrm{M}$ CAPE for $24,48,72$, and $96 \mathrm{~h}$, respectively, compare to untreated controls (Fig. 1). On the other hand, we have observed 10, 21 , and $56 \%$ decreases in cell proliferation exposed to 0.1 , 1 , and $10 \mu \mathrm{M}$ CAPE for $72 \mathrm{~h}$.

We conducted the same set of experiments in order to determine the cell viabilities by trypan blue assay. The viability assay results were in agreement with cytotoxicity analyses and revealed the dose- and time-dependent decreases in viability of CCRF-CEM cells in response to CAPE. As shown in Fig. 2, viable CCRF-CEM cell population were $65,59,13$, and $3 \%$ in $10 \mu \mathrm{M}$ CAPE-treated and $24,48,72$, and $96 \mathrm{~h}$ incubated cells, respectively, when compared to untreated controls (Fig. 2). The application of

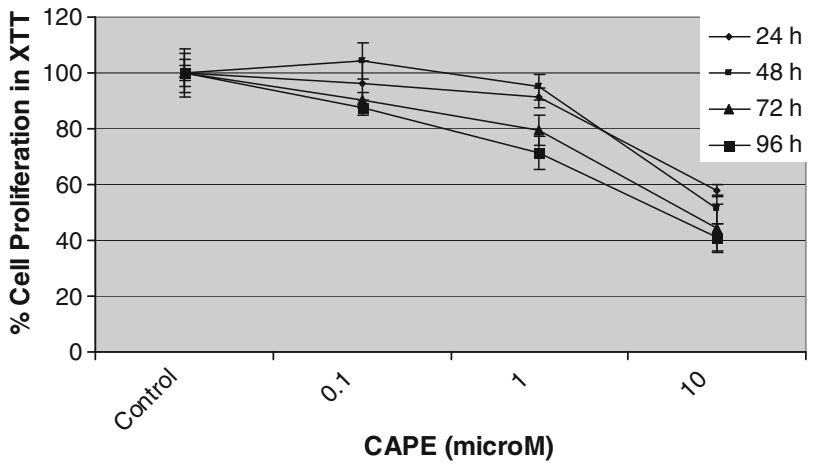

Fig. 1 Effects of CAPE on the growth of CCRF-CEM cells. The IC50 concentration of CAPE was calculated from cell proliferation plots. The XTT assays were performed using triplicate samples in at least two independent experiments. Statistical significance was determined using Student's $t$ test, and $(P<0.05)$ was considered significant 
$0.1,1$, and $10 \mu \mathrm{M}$ CAPE for $72 \mathrm{~h}$ resulted in 85,79 , and $13 \%$ viability in CCRF-CEM cells.

Effect of CAPE treatment on early and late apoptosis in CCRF-CEM cells

In order to examine apoptotic effects of CAPE on CCRFCEM cells, the cells were exposed to $10 \mu \mathrm{M}$ CAPE for 24 , 48, 72, and $96 \mathrm{~h}$, and both early and late apoptosis were evaluated by using Cell Death Detection ELISA ${ }^{\text {PLUS }}$ assay. In parallel with the previous data, the results revealed that there were time-dependent increases in apoptotic cells. About 5, 6, 29, and 39\% of CCRF-CEM cell population were in early apoptosis in response to $10 \mu \mathrm{M} \mathrm{CAPE}$ for 24 , 48,72 , and 96 h, respectively. Late apoptotic cell population in response to $10 \mu \mathrm{M}$ CAPE in CCRF-CEM cells for the same periods of time were determined to be $0,21,30$, and $25 \%$, respectively (Fig. 3).

Changes in apoptotic index in response to CAPE in CCRF-CEM cells

We evaluated apoptosis by Cell Death Detection ELISA assay. As shown in Fig. 4, the results revealed that there were 1.24-, 1.39-, 1.18-, 1.18-fold increases in apoptotic index in CCRF-CEM cells treated with $10 \mu \mathrm{M}$ CAPE for 24, 48, 72, and $96 \mathrm{~h}$ when compared to untreated controls (Fig. 4).

Loss of mitochondrial membrane potential

in CCRF-CEM cells exposed to CAPE

Changes in mitochondrial membrane potential in CAPEapplied CCRF-CEM cells were observed under fluorescence microscope and determined by flow cytometry.

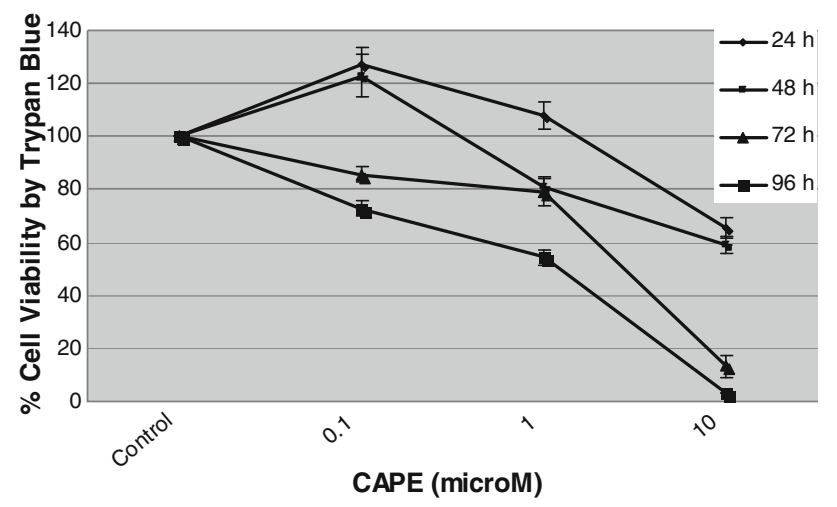

Fig. 2 Effects of CAPE on the viability of CCRF-CEM cells. Trypan blue dye exclusion assays were performed using triplicate samples in at least two independent experiments. Statistical significance was determined using Student's $t$ test, and $(P<0.05)$ was considered significant

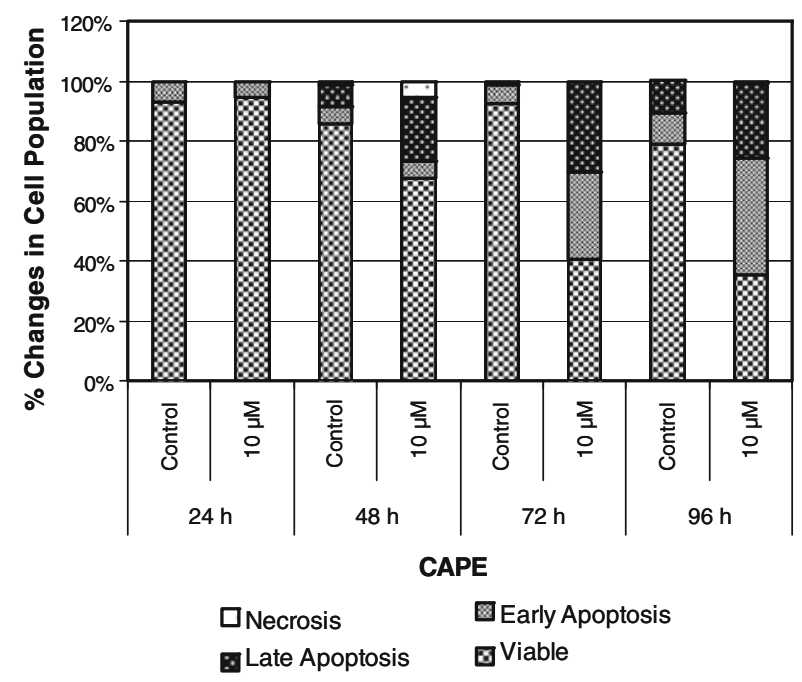

Fig. 3 Percent changes in early and late apoptosis in CAPE-treated CCRF-CEM cells. Statistical significance was determined using Student's $t$ test, and $P<0.05$ was considered significant

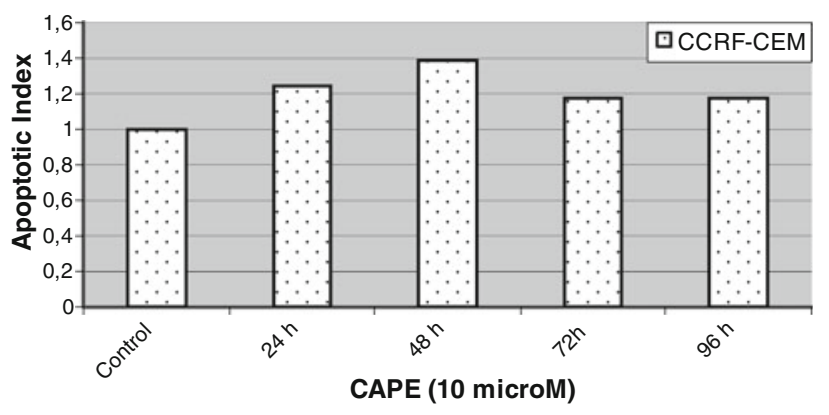

Fig. 4 Changes in apoptotic index in CCRF-CEM cells exposed to CAAPE. Statistical significance was determined using Student's $t$ test, and $P<0.05$ was considered significant

Under fluorescence microscope, we observed that application of $10 \mu \mathrm{M}$ CAPE resulted in significant accumulation of JC-1 dye in cytoplasm when compared to untreated controls (Fig. 5). Treatment of CCRF-CEM cells with $10 \mu \mathrm{M}$ CAPE resulted in cell death as detected by flow cytometry. There were 29,45 , and $22 \%$ increases in death CCRF-CEM cell population in response to $10 \mu \mathrm{M}$ CAPE for 24,48 , and $72 \mathrm{~h}$, respectively, when compared to untreated controls (Fig. 6).

\section{Discussion}

The numbers of chemotherapeutic agents extracted from natural sources for the treatment of various types of cancers have been increasing recently. Complications related to chemical drugs forced scientists to develop novel treatment agents for cancer. Drugs originating from plants are strong potential agents not only since they have strong antitumor properties but also because they do not have any harmful 

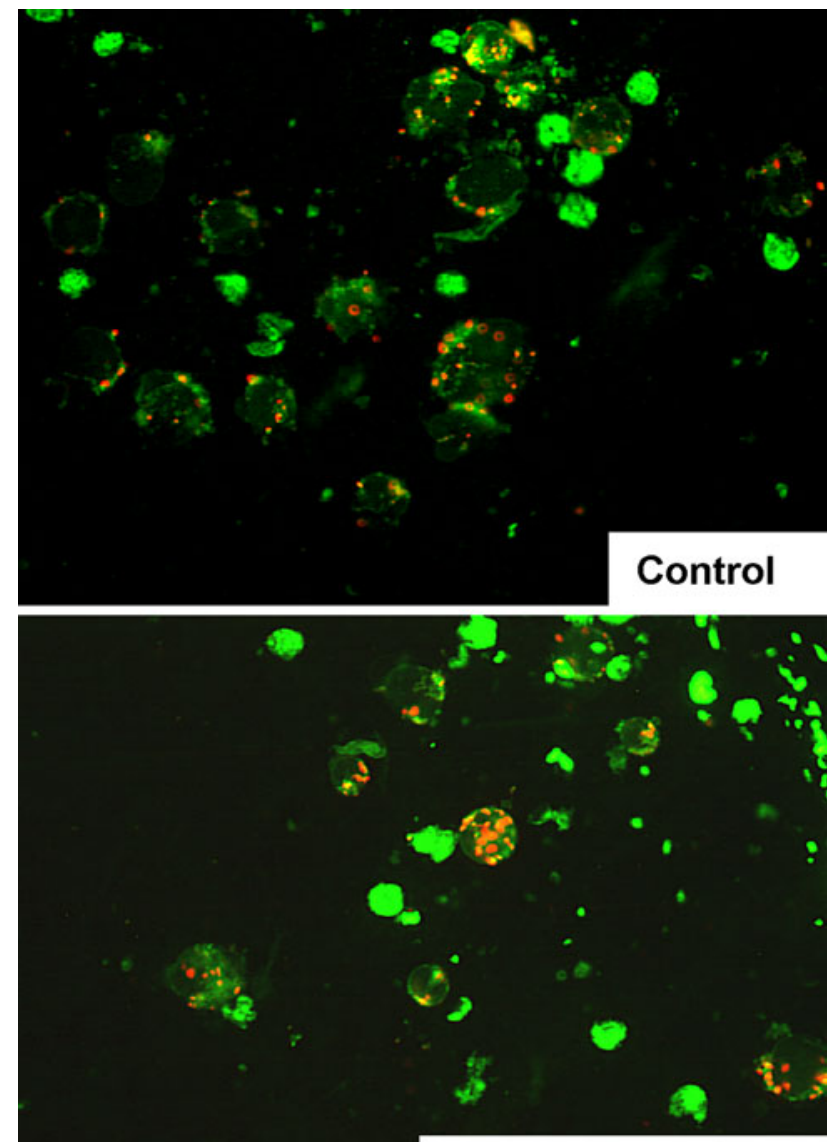

Cape 10 microM

Fig. 5 Micropicture of CCRF-CEM cells treated with CAPE

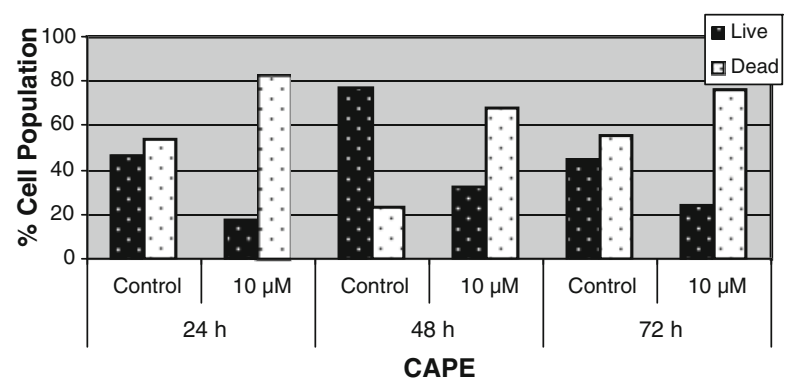

Fig. 6 Percent cell population in live/dead cells by loss of mitochondrial membrane potential by flow cytometry. Statistical significance was determined using Student's $t$ test, and $P<0.05$ was considered significant

effects on normal healthy cells (Cassileth et al. 2008; Engdal et al. 2009).

Recently, caffeic acid phenethyl ester (CAPE), obtained from honeybee propolis (Grunberger et al. 1998), has attracted notice in that it represented antitumoral (Chiao et al. 1995), anti-inflammatory (Michaluart et al. 1999; Orban et al. 2000), antiviral (Fesen et al. 1994), antioxidant (Bhimani et al. 1993), and anti-angiogenic (Liao et al.
1999) effects. Although the ability of CAPE to induce apoptosis has been reported for various types of cancer, very little is known about the effects of CAPE on human CCRF-CEM cells (Michaluart et al. 1999; Fesen et al. 1994; Chiao et al. 1995; Grunberger et al. 1998; Orban et al. 2000; Bhimani et al. 1993; Liao et al. 1999).

We conducted this study to examine whether CAPE has cytotoxic and apoptotic effects on CCRF-CEM cells and, if so, to investigate the mechanisms involved in cell death. The results of XTT cell proliferation and trypan blue viability assays revealed that CAPE has decreased proliferation and viability of CCRF-CEM cells in a dose- and time-dependent manner. On the other hand, in agreement with these results, apoptosis assay results also showed a dose- and time-dependent increases in apoptotic cell population in response to CAPE when compared to untreated controls. Flow cytometry and fluorescence microscope results revealed that CAPE induces apoptosis through induction of mitochondrial dysfunction, as demonstrated by the loss of mitochondrial membrane potential. It is very well known in the literature that apoptosis can be triggered by many internal and external stimuli, but mitochondria (mitochondrial membrane potential) are a common intersection point for all apoptotic pathways. As the numbers of permeability transition pores are increased which results in decreases in mitochondrial depolarization and release of calcium, caspase are activated and apoptosis is triggered. Thus, many internal and external stress generating factors result in the loss of mitochondrial membrane potential. Induction of apoptosis through loss of mitochondrial membrane potential was previously shown in K562 and Meg-01 chronic myeloid leukemia cells in response to imatinib, in acute lymphoblastic cells in response to resveratrol, in T-lymphoma cells in response to genistein, in HL60 cells in response to Hoechst 33342, and in acute lymphoblastic leukemia cells in response to resveratrol (Baran et al. 2007b, c; Zunino and Storms 2006; Baxa et al. 2005; Chen et al. 2004).

In agreement with our results, it was recently shown by two different groups that CAPE induces apoptosis in human U937 myeloid leukemia cells through mitochondrial pathway but not through death receptors or ER-mediated apoptosis (Dörrie et al. 2001). Chen et al. (2008) have shown that CAPE induced a time-dependent increase in apoptotic cell population through mitochondrial dysfunction in human BcPC-3 pancreatic cancer cells. The same group has also showed the loss of mitochondrial membrane potential to about half of the untreated level in response to CAPE only after $6 \mathrm{~h}$ in HL60 cells (Chen et al. 2001). It was reported by several groups that CAPE inhibited cell growth and proliferation and triggered apoptosis in SW480 and HCT116 colorectal cancer cells, ME180 cervical cancer cells, C6 glioma cells, and MCF-7 
breast cancer cell (He et al. 2006; Wang et al. 2005; Hung et al. 2003; Lee et al. 2003; Watabe et al. 2004; Burke et al. 1995). On other hand, it was shown by Chung and his coworkers that besides inhibition of cell proliferation, CAPE also has inhibitory effects on invasion and metastasis through suppression of MMP-9 enzyme and downregulation of expression of NF-KB (Chung et al. 2004). CAPE has also been shown to have cell cycle arrest and DNA, RNA, and protein inhibition ability on HL60 cells (Chen et al. 1996). Interestingly, several studies showed that CAPE has no cytotoxic and apoptotic effects on normal healthy cells (Lee et al. 2003). It was shown in 2005 that CAPE application increased sensitivity of CT26 colorectal adenocarcinoma cells to ionizing radiation in $\mathrm{BALB} / \mathrm{c}$ mouse while showed no cytotoxic effects on bone marrow, kidney, and liver (Chen et al. 2005). These studies suggest that CAPE has cytotoxic effects only on malignant cells.

In conclusion, we have demonstrated for the first time that human CCRF-CEM acute lymphoblastic leukemia cells exposed to increasing concentrations of CAPE undergo apoptosis in a time- and dose-dependent manner. While the complete mechanism is not clear, we have shown by this study that CAPE-induced apoptosis at least involves loss of mitochondrial membrane potential which activates caspases. Taken together, these results may suggest that active component of propolis, CAPE, may have chemotherapeutic potential for the treatment of human acute lymphoblastic leukemia by inducing apoptosis. However, clinical outcomes of CAPE application remain to be examined before its use in clinics.

\section{References}

Asoh S, Mori T, Hayashi J, Ohta S (1996) Expression of the apoptosis-mediator Fas is enhanced by dysfunctional mitochondria. J Biochem 120:600-607

Baran Y, Salas A, Senkal CE, Bielawski J, Gunduz U, Obeid LM, Ogretmen B (2007a) Alterations of human longevity assurance gene 1 (LASS1)/sphingosine kinase-1-dependent ceramide generation and metabolism involve in the regulation of imatinibinduced apoptosis and resistance in K562 human chronic myeloid leukemia (CML) cells. J Biol Chem 282(15):1092210934

Baran Y, Gur B, Ural AU, Avcu F, Gunduz U (2007b) Upregulation of multi drug resistance genes in doxorubicin resistant human acute myelogenous leukemia cells and reversal of the resistance. Hematology 12(6):511-517

Baran Y, Ural AU, Gunduz U (2007c) Mechanisms of cellular resistance to imatinib in human chronic myeloid leukemia cells. Hematology 12(6):497-503

Baxa DM, Luo X, Yoshimura FK (2005) Genistein Induces apoptosis in $\mathrm{T}$ lymphoma cells via mitochondrial damage. Nutr Cancer 51:93-101
Berger N, Ben Bassat H, Klein BY, Laskov R (1992) Cytotoxicity of NF-kappaB inhibitors Bay 11-7085 and caffeic acid phenethyl ester to Ramos and other human B-lymphoma cell lines. Exp Hematol 35:1495-1450

Bhimani RS, Troll W, Grunberger D, Frenkel K (1993) Inhibition of oxidative stress in HeLa cells by chemopreventive agents. Cancer Res 53:4528-4533

Borrelli F, Izzo AA, Di Carlo G, Maffia P, Russo A, Maiello FM, Capasso F, Mascolo N (2002) Effect of a propolis extract and cafeic acid phenethyl ester on formation of aberrant crypt foci and tumors in the rat colon. Fitoterapia 73:38-43

Burke TR, Fesen MR, Mazumder A, Wang J, Carothers AM, Grunberger D, Driscoll J, Kohn K, Pommier Y (1995) Hydroxylated aromatic inhibitors of HIV-1 integrase. J Med Chem 38:4171-4178

Cassileth B, Yeung KS, Gubili J (2008) Herbs and other botanicals in cancer patient care. Curr Treat Options Oncol 9(2-3):109-116

Chen JH, Shao Y, Huang MT, Chin CK, Ho CT (1996) Inhibitory effect of caffeic acid phenethyl ester on human leukemia HL-60 cells. Cancer Lett 108(2):211-214

Chen Y, Shiao M, Wang SY (2001) The antioxidant caffeic acid phenethyl ester induces apoptosis associated with selective scavenging of hydrogen peroxide in human leukemic HL-60 cells. Anti Cancer Drugs 12:143-149

Chen JC, Zhang X, Singleton TP, Kiechle FL (2004) Mitochondrial membrane potential change induced by Hoechst 33342 in myelogenous leukemia cell line HL-60. Ann Clin Lab Sci 34:458-466

Chen YJ, Liao HF, Tsai TH, Wang SY, Shiao MS (2005) Caffeic acid phenethyl ester preferentially sensitizes CT26 colorectal adenocarcinoma to ionizing radiation without affecting bone marrow radioresponse. Int J Radiat Oncol Biol Phys 63:1252-1261

Chen MJ, Chang WH, Lin CC, Liu CY, Wang TE, Chu CH, Shih SC, Chen YJ (2008) Caffeic acid phenethyl ester induces apoptosis of human pancreatic cancer cells involving caspase and mitochondrial dysfunction. Pancreatology 8:566-576

Chiao C, Carothers AM, Grunberger D, Solomon G, Preston GA, Barrett JC (1995) Apoptosis and altered redox state induced by caffeic acid phenethyl ester (CAPE) in transformed rat fibroblast cells. Cancer Res 55:3576-3583

Chung TW, Moon SK, Chang YC, Ko JH, Lee YC, Cho G, Kim SH, Kim JG, Kim CH (2004) Novel and therapeutic effect of caffeic acid and caffeic acid phenyl ester on hepatocarcinoma cells: complete regression of hepatoma growth and metastasis by dual mechanism. FASEB J 18:1670-1681

Cossarizza A, Baccarani-Contri M, Kalashnikova G, Franceschi C (1993) A new method for the cytofluorimetric analysis of mitochondrial membrane potential using the J-aggregate forming lipophilic cation 5, 50, 6, 60-tetrachloro-1, 10, 3, 30 tetraethylbenzimidazolcarbocyanine iodide (JC-1). Biochem Biophys Res Commun 197:40-45

Crazzolara R, Bendall L (1999) Emerging treatments in acute lymphoblastic leukemia. Curr Cancer Drug Targets 9:19-31

Demestre M, Messerli SM, Celli N, Shahhossini M, Kluwe L, Mautner V, Maruta H (2009) CAPE (caffeic acid phenethyl ester)-based propolis extract (Bio 30) suppresses the growth of human neurofibromatosis (NF) tumor xenografts in mice. Phytother Res 23:226-230

Dörrie J, Gerauer H, Wachter Y, Zunino SJ (2001) Resveratrol induces extensive apoptosis by depolarizing mitochondrial membranes and activating caspase- 9 in acute lymphoblastic leukemia cells. Cancer Res 61:4731-4739

Engdal S, Klepp O, Nilsen OG (2009) Identification and exploration of herb-drug combinations used by cancer patients. Integr Cancer Ther 8(1):29-36 
Fesen MR, Pommier Y, Leteurtre F, Hiroguchi S, Yung J, Kohn KW (1994) Inhibition of HIV-1 integrase by flavones, caffeic acid phenethyl ester (CAPE) and related compounds. Biochem Pharmacol 48:595-608

Gogvadze V, Orrenius S, Zhivotovsky B (2006) Multiple pathways of cytochrome $c$ release from mitochondria in apoptosis. Biochim Biophys Acta 1757:639-647

Gogvadze V, Orrenius S, Zhivotovsky B (2008) Mitochondria in cancer cells: what is so special about them? Trends Cell Biol $18: 165-173$

Grunberger D, Banerjee R, Eisinger K, Oltz EM, Efros L, Caldwell M, Estevez V, Nakanishi K (1998) Preferential cytotoxicity on tumor cells by caffeic acid phenethyl ester isolated from propolis. Experientia 44:230-232

He YJ, Liu BH, Xiang DB, Qiao ZY, Fu T, He YH (2006) Inhibitory effect of caffeic acid phenethyl ester on the growth of SW480 colorectal tumor cells involves beta-catenin associated signaling pathway downregulation. World J Gastroenterol 12:4981-4985

Hung MW, Shiao MS, Tsai LC, Chang GG, Chang TC (2003) Apoptotic effect of caffeic acid phenethyl ester and its ester and amide analogues in human cervical cancer ME180 cells. Anticancer Res 23:4773-4780

Lee YJ, Liao PH, Chen WK, Yang CY (2000) Preferential cytotoxicity of caffeic acid phenethyl ester analogues on oral cancer cells. Cancer Lett 153:51-56

Lee YJ, Kuo HC, Chu CY, Wang CJ, Lin WC, Tseng TH (2003) Involvement of tumor suppressor protein p53 and p38 MAPK in caffeic acid phenethyl ester-induced apoptosis of C6 glioma cells. Biochem Pharmacol 66:2281-2289

Li D, Saldeen T, Romeo F, Mehta JL (2000) Oxidized LDL upregulates angiotensin II type 1 receptor expression in cultured human coronary artery endothelial cells: the potential role of transcription factor NF-kappaB. Circulation 102:1970-1976

Liao H, Chen Y, Liu J (1999) Inhibitory effect of caffeic acid phenyl ester on angiogenesis, tumor invasion, and metastasis. J Agric Food Chem 51:7907-7912

Michaluart P, Masferrer JL, Carothers AM, Subbaramaiah K, Zweifel BS, Koboldt C, Mestre JR, Grunberger D, Sacks PG, Tanabe T, Dannenberg AJ (1999) Inhibitory effects of caffeic acid phenethyl ester on the activity and expression of cyclooxygenase- 2 in human oral epithelial cells and in a rat model of inflammation. Cancer Res 59:2347-2352

Neuzil J, Weber T, Gellert N, Weber C (2001) Selective cancer cell killing by alpha-tocopheryl succinate. Br J Cancer 84(1):87-89

Neuzil J, Wang XF, Dong LF, Low P, Ralph SJ (2006) Molecular mechanism of 'mitocan'-induced apoptosis in cancer cells epitomizes the multiple roles of reactive oxygen species and Bcl-2 family proteins. FEBS Lett 5(22):5125-5129

Neuzil J, Dyason JC, Freeman R, Dong LF, Prochazka L, Wang XF, Scheffler I, Ralph SJ (2007) Mitocans as anti-cancer agents targeting mitochondria: lessons from studies with vitamin $\mathrm{E}$ analogues, inhibitors of complex II. J Bioenerg Biomembr 39:7265-7282

Orban Z, Mitsiades N, Burke TR Jr, Tsokos M, Chrousos GP (2000) Caffeic acid phenethyl ester induces leukocyte apoptosis, modulates nuclear factor-kappa B and suppresses acute inflammation. Neuroimmunomodulation 7:99-105

Rao CV, Desai D, Kaul B, Amin S, Reddy BS (1992) Effect of caffeic acid esters on carcinogen-induced mutagenicity and human colon adenocarcinoma cell growth. Chem Biol Interact 84(3):277-290

Sahin F, Avci CB, Avcu F, Ural AU, Sarper M, Omay SB, Saydam G (2007) Red grape seed extract and its compound resveratrol exert cytotoxic effect to various human cancer lines. Turk J Hematolol 24:102-109

Salvioli S, Ardizzoni A, Franceschi C, Cossarizza A (1997) JC-1, but not DiOC6(3) or rhodamine 123, is a reliable fluorescent probe to assess Dc changes in intact cells:Implications for studies on mitochondrial functionality during apoptosis. FEBS Lett 411:77-82

Schmidt-Mende J, Gogvadze V, Hellström-Lindberg E, Zhivotovsky B (2006) Early mitochondrial alterations in ATRA-induced cell death. Cell Death Differ 13:119-128

Son S, Lewis BA (2002) Free radical scavenging and antioxidative activity of cafeic acid amide and ester analogues: structure activity relationship. J Agric Food Chem 50:468-472

Sud'ina GF, Mirzoeva OK, Pushkareva MA, Korshunova GA, Sumbatyan NV, Varfolomeev SD (1993) Caffeic acid phenethyl ester as a lipoxygenase inhibitor with antioxidant properties. FEBS Lett 329:21-24

Swerts K, de Moerloose B, Dhooge C, Noens L, Laureys G, Benoit Y, Philippé J (2004) Comparison of two functional flow cytometric assays to assess P-gp activity in acute leukemia. Leuk Lymphoma 45(11):2221-2228

Wang D, Xiang DB, He YJ, Li ZP, Wu XH, Mou JH, Xiao HL, Zhang $\mathrm{QH}$ (2005) Effect of caffeic acid phenethyl ester on proliferation and apoptosis of colorectal cancer cells in vitro. World $\mathrm{J}$ Gastroenterol 11:4008-4012

Watabe M, Hishikawa K, Takayanagi A, Shimizu N, Nakaki T (2004) Caffeic acid phenethyl ester induces apoptosis by inhibition of NFkappaB and activation of Fas in human breast cancer MCF-7 cells. J Biol Chem 279:6017-6026

Wolvetang EJ, Johnson KL, Krauer K, Ralph SJ, Linnane AW (1994) Mitochondrial respiratory chain inhibitors induce apoptosis. FEBS Lett 339:40-44

Yu W, Sanders BG, Kline K (2003) RRR-alpha-tocopheryl succinateinduced apoptosis of human breast cancer cells involves Bax translocation to mitochondria. Cancer Res 63(10):2483-2491

Zunino SJ, Storms DH (2006) Resveratrol-induced apoptosis is enhanced in acute lymphoblastic leukemia cells by modulation of the mitochondrial permeability transition pore. Cancer Lett 240:123-134 